\title{
ARTIFICE SPECIFICATIONS AS EXPRESSIVE MEANS OF THE MODERN CINEMATOGRAPHY
}

\section{Zhukovin O. V.}

\section{INTRODUCTION}

Digital technologies are becoming elements of a new artistic reality, which has a significant impact on the psychology of aesthetic perception. A considerable amount of factual material has been accumulated in various countries where new technologies are being actively developed, requiring scientific reflection in the context of culture, including in the interests of improving artistic practice. "Cinema is undergoing major changes at all levels. Examples of non-film movies, videotapes, prints, movie projectors, and collective screening appear in the darkened auditorium. Directors and screenwriters come up with plots, shoot, and edit movies using computer-based image manipulation from the desktop. It is not just about the invasion of computer graphics into the film process, but about the profound changes of the concept itself. For the viewer, the presence of digital cinema is reflected in a large number of special effects produced on or using the computer" ${ }^{1}$ [1].

The same can be said about theatrical acts. With computer graphics and laser installations indoors or outdoors, you can see a large action image in the air. One of the latest advances in computer technology is the virtual promoter (online promoter). It is a construction of transparent acrylic with a thickness of not more than one centimeter, with the application of unique material on it. An image of a person is projected onto the structure. Thanks to the special projection back-film, under intense artificial lighting, the projected image remains very bright. The virtual promoter is equipped with speakers to transmit the audio series. The extensive use of this multimedia system is astounding.

Consider the genesis of computer tricks. One of the parents of computer graphics experts called Ivan Sutherland, who, as a graduate student at Massachusetts Institute of Technology (MIT), 1963, developed the program Sketchpad, which allowed to create simple graphic objects. In doing so, he was able to lay the groundwork for the graphical user interface by changing the way humans and computers interact.

After covering a thesis in Computer Science, Ivan and Dr. David Evans opened the first Computer Graphics Department at the University of Utah.

\footnotetext{
${ }^{1}$ Terakopyan M. L. (2007) Back to the Future: Computer Technologies in Cinema. Iskusstvo kino, 9, pp. 65-71.
} 
Young and ambitious colleagues have set a noble goal - to attract talented, enthusiastic scientists to develop a high-tech industry. Ed Catmull, now president of Walt Disney Animation Studio, was among the students. Ed Catmull was first who modeled a relatively complex object. The object for modeling was the brush of his hand.

Jim Blinn, the creator of bump mapping and environment mapping, the first computer animations for NASA and, of course, the famous blinn material, was a student at Ivan Sutherland. About myself, Blinn often said this: "As a kid, I used to love collecting postage stamps, but now I prefer to collect margarine packages and algorithms for drawing circles." Ivan Sutherland treated his student with great respect, and in an interview, a famous scientist remarked: "There are no more than a dozen true computer graphics creators in the world, and Jim is half of the total." ${ }^{2}$ [2].

The crazy concentration of intellectual energy around the University of Utah, apparently, did not allow anyone to sleep peacefully and made people think and create irresistibly. For example, the Phong shading technique was developed by Vietnamese 3D artist Bi-Tung Fong, who was also a student at the Utah Computer Graphics Department. The principle of Gouraud shading a method used in computer graphics to simulate differences in light and color on the surface of the object - was born in the mind of a French scientist Henri Guro, now teaching at the University of Utah. These events occurred in the 1970s. In 1967, the University of Toronto came up with morphing, and a year later, Ray Tracing appeared. All of the above has been used extensively by CG specialists to this day ${ }^{3}[2]$.

Early CGI images were created in vector graphics that were inferior to the bitmap quality. In the 1970s, with the increase in the computing power of computers, experts began to work mainly with a pixel matrix (bitmap). Synthetically created and externally realistic objects first appeared in television commercials.

\section{Stage movies with special effects of the 1970s-1990s}

The novel of computer graphics from cinema began to swirl in the second half of the 1980s, and in the 1970s, there were only single projects where CG was usually used to visualize the computer interface. This was the case in Star Wars (1977) when viewers were shown a virtual rebel trainer with a wireframe model of the tunnel in "Death Star" and Ridley Scott's "Alien" (1979), where pilots sat on a planet looking at monitors displaying the

\footnotetext{
${ }^{2}$ Meerov K (2012) Historical excursion into the universe of special effects III. Professional'nyy zhurnal o spetseffektakh v kino CINEFEX. URL: http://cinefex.ru/articles/detail.php?ID =442.

${ }^{3}$ Ibid.
} 
landscape. The first was a fantastic painting, "Westworld" (1973), several scenes of which were digitally processed: cinematographers with the help of two-dimensional graphics depicted the infrared field of view of the work.

"Star Wars" by George Lucas and "Close Encounters of the Third Kind" (1977) by Steven Spielberg played a decisive role in the life of the movie industry, ultimately reinforcing its success with the development of the jawbone blockbuster "Jaws" by Spielberg (1975). The entertaining movie productions with a lot of special effects, first of all, were visual dishes of the day. They reworked at the full capacity of the studio at the movie studios, and George Lucas quickly opened his own company, Industrial Light \& Magic, which became the market leader.

Overall, Hollywood is still biased against the prospect of creating images on a computer, relying on time-tested optical and mechanical effects. George Lucas' film, thanks to his commercial success, began a special effects revolution that ended with the CG industry becoming established in the second half of the 1990s. The visuals came out stunning and convincing in every detail.

The pioneering was the invention of Richard Edlund (under the direction of John Dykstra) of a computerized rather than a mechanical motion control unit. A program was downloaded into the computer, according to which the camera crane moved in a particular direction and at a given speed. In doing so, the camera could repeat the same movement the required number of times. The installation was also used to control models, many of which were shot on a blue screen. In the same way, artists created background images, animators by frame animated a game of chess under the direction of Phil Tippet. Besides, the "Star Wars" painting features stunning makeup and a scene of flying through the "Death Star" tunnel, created with computer graphics. Thus, the Oscar for Best Visual Effects was well deserved.

The 1982 film "Trone" made the technological furor, becoming the first art tape to use computer animation and graphics in the amount of 16 minutes of computer animation and 30 minutes of traditionally drawn effects. It is even believed that the term CGI (computer-generated image) was used by one of the reviewers of this picture. The tape also featured the first fully digital character, Beat, who accompanied the protagonist at the beginning of his journey inside the program. The computer graphics were in the hands of four third-party studios hired by Disney to implement the 1,100 effect plans.

However, most of the game scenes inside the virtual world were created by traditional techniques that formed the original process, called "Backlit animation." The actors were filmed on a black-and-white film on a black background. The images were split into layers, photographed each element separately with control light through color filters, and re-assembled on an optical printer through masks. The process was lengthy and expensive. 
Despite the novelty of the video series, the movie did not become a box office hit and did not accelerate the process of computer graphics penetration into the cinema, even on the contrary - slowed down slightly, but research in this area continued.

In the same year, "Star Trek II: The Wrath of Khan" appeared with a minute CGI-episode of the birth of the planet. The tape is notable for being the first one with a digital matte-painting background in one of the scenes. Then there was the "Young Sherlock Holmes" film with a computer knight model and three-dimensional animated shorts by one of the Lucasfilm divisions (after sold renamed Pixar).

The 1980s were far more commercially successful than the 1970s, but the cost of producing paintings increased. If at the beginning of the decade the average price of a movie was $\$ 10$ million, then by the end of it already 23 million. Blockbusters were performed on screens one by one, bringing studios hundreds of millions of dollars.

Special effects have become not only an instrument but also one of the leading "chips" of the movie show. Important inventions have been made in the technical field of film production. Thus, in 1987, The Computer Film Company released a scanner to transfer information from film to computer as files for further processing. In 1995, Mike Baudry, along with other specialists, received a special technical Oscar for this innovation. Besides, the editing systems were improved, which made it easier for the directors to edit, and finally, a program for 3D modeling and animation Softimage 3D (1988) was released.

In 1989, James Cameron, the Abyss, appeared on the screen, one of the milestones for the emerging computer graphics industry. In this picture, the alien creature Pseudopod became the first character to be entirely generated in the 3D efforts of ILM specialists. Seventy-five seconds of computer animation took six months of life for artists. The composing of the creature was not digital, but analog, that is, optical. The project received an Oscar for best visual effects as well as finally convincing even skeptics that CG technology has a vast potential that has yet to be revealed ${ }^{4}$ [2].

Therefore, let's define the stage films of the period under consideration.

"Star Wars sequel trilogy" (1977, 1980, 1983). Each of the three films received an Oscar for visual effects. The first tape was noticeable with the introduction of the first computerized motion control system. The second features a compelling Jodi doll and an early form of dynamic motion-picture animation (go-motion) invented by Phil Tippet. The third picture used the same technique plus a huge Jabbi animatronic doll, the largest at the time.

${ }^{4}$ Meerov K (2012) Historical excursion into the universe of special effects III. Professional'nyy zhurnal o spetseffektakh $\mathrm{v}$ kino CINEFEX. URL: http://cinefex.ru/articles/ detail.php? ID =442. 
"Close Contacts of the Third Kind" (1977). The first great Steven Spielberg movie with visual effects. During the filming, the filmmakers operated both traditional techniques and the newest at the time. It's about motion control systems. They also built models and thumbnails that were shot with an increased perspective. The picture was nominated for an Oscar for visual effects, but the statuette went to Star Wars.

"Trone" (1982). One of the main Stephen Lisberger films with computer graphics in cinema history.

"Blade Runner" (1982). One of Ridley Scott's latest notable sci-fi films made in the traditional special effects technique without computer graphics. The production department built scenery, layouts, the operator shot with an increased perspective, and the artists increased the space of the frame due to the painted backdrops. The film did not pay off, but gained cult status and eventually became a classic, making a significant impact on the subsequent fantastic films.

"Who Framed Roger Rabbit" (1987). Robert Zemeckis's film has been in production for almost two years. The budget of the picture was a record at that time, \$ 70 million. Zemeckis and 375 animators succeeded in making the most entertaining film that brought together real actors and cartoon characters in one shot. The hand-drawn animation is available in 82,000 frames that were optically combined with ILM Studio staff. To make the cartoon characters look more authentic, they were made not with black or gray shadows, but with blotches of color. The film was awarded the Academy Award for Best Visual Effects.

"The Abyss" (1989). The underwater scenes of James Cameron's movie were filmed in the most significant water tank ever used in shooting at the time. The alien creature Pseudopod, formed from ocean water, was modeled and animated in 3D by three-dimensional ILM and rendered in one of the first versions of Renderman. Also, the picture became the first tape to reproduce the environment on a computer using the technique now known as cameraprojection. The surrounding environment was photographed from all angles and then reproduced on a computer using the photo material as a texture. This made it possible to combine the CGI characters with the cast painstakingly.

In the 1990s, digital technologies began to reclaim space. In 1990, Paul Verhoeven's super hit "Remember Everything" hit the screens. The project became the latest blockbuster where the lion's share of special effects was created without the use of computer graphics. The only CGI-image was the scene of the passage of the hero Schwarzenegger through X-ray before being sent to Mars. A year later, James Cameron's "Terminator 2: Judgment Day" came out, which became a frontier, overcoming which the industry was no longer able to abandon CG technology. 
The film has revolutionized technology as much as changing Hollywood's attitude toward computer graphics. The studios have seen that not only traditional special effects but digital ones also produce results that can surprise the public to the heart. The only obstacle on the road to complete victory was the cost of software and hardware, so computer graphics and animation for a long time were not a lifting cost item available only to expensive projects. SGI Graphics Stations and the first modeling, animation, and compositing programs cost huge money. Still, by the early 21st century, the situation had changed by dozens of times, and the performance of PC machines had come closer to SGI's capacity, bankrupting a company that failed to find itself new market conditions.

In 1993, he made his "Jurassic Park" debut, which for some time, became the most iconic picture in cinema history. Unlike Terminator 2, Spielberg's painting is a much more complex and advanced 3D animation. Thanks to ILM specialists modeling at Alias Studio, animated in Softimage 3D and rendered in Renderman, extinct dinosaurs came to life on screen. In addition to the CGI of prehistoric creatures, close-up pictures featured radiocontrolled animated dolls designed by Stan Winston. Also tremendous was the extensive experience in the frame-by-frame animation of Phil Tippet, who developed the DID - Dinosaur Input Device.

After the stunning success of "Jurassic Park", Hollywood has invested a lot of money in computer-graphics projects, and films have been released one after the other, where the number of CGI plans has grown like a yeast: "Mask," "Casper," "Jumanji," "Heart of the Dragon", "Independence Day", "Man in Black" and more. With the increase in the spectacle, the demand for graphics has grown, and as a result, the production of CG and visual effects has become a business - an entire industry has emerged.

Dozens of studies have appeared on the market. In 1994, James Cameron and Stan Winston discovered Digital Domain, which became one of the leaders in visual experience alongside ILM, Rhythm \& Hues, and Sony Imageworks. In addition to commercial software solutions, large CG studios have influential $\mathrm{R} \& \mathrm{D}$ departments to develop graphics, because each film is a new creative task that often requires a non-standard tool.

In 1995, after a series of successful short films, Pixar released the first fully-fledged animated movie, "Toy Story." At the time, it was hard to imagine, but the success of the project in some five to seven years made two-dimensional animation anachronistic.

In 1999, Wachowski's The Matrix was released, the best fantasy film of the 1990s, in which visual effects perfectly complement the story and set the trend in their development over the coming years. Surprisingly, little-known Wachowski went around George Lucas himself, who released the "Star Wars: The Hidden Threat" in the same year, which failed to become known as a styling project, unlike "The Matrix." 
The motion capture technology in the second half of the 1990s gradually gained more followers. The technology of the gaming world is shifting and is used when you need to animate an anthropomorphic creature. Certainly, James Cameron used mocap to animate digital characters wandering the Titanic deck. Then with the development of software and recording devices, cinematographers begin not only to capture movement with this technology but also to "capture" emotions, read facial expressions - in general, transmit acting. The technique was renamed performance capture and has been used in paintings such as "Star Wars: The Hidden Threat" (1999), "Final Fantasy: The Spirits Within" (2001), "Lord of the Rings: Two Fortresses" (2002), and "Lord of the Rings: Return of the King" (2003), but it receives the leading apologist in the oeuvre of Robert Zemeckis ${ }^{5}$ [2].

Therefore, let's define the stage films of the period under consideration.

"Terminator 2: Judgment Day" (1991). The most expensive movie (directed by James Cameron) at the time of the rental without inflation. The picture skillfully combined traditional special effects - miniature, pyrotechnics, prosthetics and false makeup, animatronics - with computer animation, which was pure in the form of 6 minutes. The liquid terminator of the T-1000 model was generated and animated by the efforts of ILM artists. It was the first movie where computer effects were digitally assembled. The film received four Academy Awards, including a statuette for visual effects.

"Jurassic Park" (1993). This Steven Spielberg project finally convinced that computer graphics would be the primary tool for creating effects. The movie has less than 50 plans with animated dinosaurs, but it was a huge leap forward from liquid metal to a living creature, re-created by ILM experts. In addition to the dinosaur animation, they also digitally swapped faces and created a 3D car. The tape was awarded three Academy Awards, including for visual effects.

"Toy Story" (1995). The first full-length, three-dimensional animated film created by Pixar in collaboration with Walt Disney. Interestingly, 400 character models occupied 1,000 megabytes of disk space and numbered 3,500 textures. The rendering required 500,000 hours.

"Titanic" (1997). The highest-grossing movie of the 20th century (directed by James Cameron). 11 Oscars, including for visual effects. The creators demonstrated a great combination of physical and visual effects. Somewhere the layout of the ship was shot, and somewhere there is a computer model when the camera was panning over it with an intelligent trajectory. Also, Digital Domain 3D changers have changed the background, hosted the required

${ }^{5}$ Meerov K (2012) Historical excursion into the universe of special effects III. Professional'nyy zhurnal o spetseffektakh $\mathrm{v}$ kino CINEFEX. URL: http://cinefex.ru/articles/ detail.php?ID $=442$. 
landscape on a computer, generated water, dolphins, and various atmospheric effects such as smoke from a ship's pipe.

"The Matrix" (1999). The cult and one of the most spectacular films by director Andy and Larry Wachowski. One of the first movies where so many scenes were played on a computer using photos. Now it is a widespread technique called camera projection. The bullet-time effect remembered most of the feed. The actors were filmed in the green pavilion, securing it in a suspended state using a rope system. One hundred twenty-two film cameras were placed on the perimeter of the site, the shutter of which was operated synchronously. The scene was pre-rehearsed to understand where cameras should be placed and at what intervals they should shoot. Later, the resulting images were digitized, refined on a computer; and when playing at the required directors' speed, the movement with the fly of the actor. Thanks to the program, specialists were able to speed up or slow down the movement. The film received three Academy Awards, including for visual effects.

\section{Stage Movies with Special Effects 2000-2018}

The beginning of the 21st century in the world of cinema was marked by the announcement of George Lucas that "Star Wars: Episode II - Attack of the Clones" will be the first film to be shot entirely on a digital camera. Such a camera was designed by Sony Corporation, which obtained the support of Panavision. The Sony Hdw-f900 was introduced soon. It is noteworthy that "Clone Attack" was not the first film made in the series. Lucas was preceded by Pitaf, who released his "Vidocq," shot on this camera a little earlier. Shooting for the moment became a trend, and soon Robert Rodriguez's (Sin City), Michael Mann (Contributor), David Fincher (Zodiac), Steven Soderbergh (Che) and many other prominent directors have adopted it. It is important to note that not all of them shot the same model on the camera because as soon as demand came, there were offers from other manufacturers: Red one, Thomson Viper, Silicon Imaging, Dalsa Origin, and others.

The digital shooting had a significant advantage over film: the convenience and complete control of the process, the ability to view the footage that day and make duplicates without fear of film overruns. Besides, the tinting period no longer required scanning and data transfer from film to computer because the information had already been digitized and transmitted directly as files. Today, with the advent of a large number of digital halls that showcase film, not from a film projector, but a hard drive, scanners without which it was impossible to imagine Digital Intermediate before, and will soon be gone in the summer. This is the case with optical printers, which have been almost entirely squeezed out by composing software at the turn of the century. 
The technology mentioned above has been successfully used in "I, Robot" (2004), "King Kong" (2005), "Matrix 2,3" and "Pirates of the Caribbean 2, 3". The impetus for the emergence of so many significant projects was the commercial and artistic success of the Lord of the Rings trilogy. The second movie in the franchise debuted the character Gollum, who made a mini-revolution. No CGI character has ever been so convincing in expressing his feelings. Later, James Cameron confessed that it was Gollum who made him believe in the creation of Na'vi.

In all the films mentioned above, the mocap characters played side by side with real actors. Robert Zemeckis went the other way, and as he showed further developments, the master was mistaken. The director decided to shoot animated 3D films, the characters of which would be people animated by the technique of capturing the actress, rather than fictional characters, beasts and more. To do this, he opened Imagemovers Studio and set about improving the technology.

The first and most commercially successful project was " The Polar Express" (2004), which, with a production budget of \$ 165 million, grossed over \$ 300 million in the worldwide box office, followed by "Beowulf" (2007) and "Christmas Story" (2009), each of which is a technological step forward, offering the viewer more realistic CGI-People (images were generated with 3D graphics) each time.

However, the authors failed to overcome the "sinister valley" (the fect of the "sinister valley" [s.pikabu.ru] hypothesis that the robot or another object that looks or acts like a human is disgusting to human observers). It is unlikely that this has caused the loss of projects. Probably, Robert Zemeckis was just stuck in the middle between a motion picture and an animated movie, offering the viewer something in the middle and not fully deciding what it would be: a cartoon or a motion picture. Be that as it may, but Disney Studio has already announced that it will close ImageMovers by the end of the year because the company did not fit into the corporate development strategy.

Also, Robert Zemeckis is not a joke about stereo imagery, doing much to restore his former popularity among Hollywood professionals. His last three projects have been shown in 3D; besides, he produced the animated movie "Monster House" in stereo format. Disney and Dreamworks Animation executives steered the show, instructing all-new animation projects to be released not only in the traditional two-dimensional but also in stereo format.

Thus, before the release of "Avatar" by James Cameron, modern viewers saw about 20 paintings made or converted to 3D. These were animated tapes, but there were also game ones, such as "Journey to the Center of the Earth" (2008), "The Final Destination" (2009), "G-Force" (2009), and others. And the 
first in the new time was the work of Robert Rodriguez - "Spy Kids 3-D: Game Over" (2003).

However, "Avatar" managed the main thing: the tape earned more at the box office than all the films mentioned above combined. The wave of success and popularity so covered everyone that it could have seemed as if there was no stereo cinema before, and Cameron invented some new cinematic design. This is not true: nothing fundamentally new was brought to work with stereotechnology. Just, in this case, the effect of over-popularity worked, when the less well-known (and compared to "Avatar" and completely unfamiliar tapes) automatically faded into the shadows.

Evolutionary changes affected the production part. It is a virtual production technique, which is a logical continuation of 3D re-engineering. James Cameron can control a virtual camera, see actors, and non-existent computer characters on his monitor in real-time. In this case, the graphics of the environment and CGI heroes were of poor quality so that the program could process it in a short time.

Will the technique of virtual filmmaking change film production? Yes, but only if it is a movie, much of the space of the one would be generated in $3 \mathrm{D}$ on a computer, as in "Avatar" or "Alice in Wonderland." In addition to the introduction of virtual production, Avatar has raised the bar of animation for photorealistic digital characters. Still, again, it is correct to talk about evolution rather than a technological revolution. The main achievement of "Avatar" is to promote the stereo format to the audience. One film has done more than ten previous ones. And there is every reason to believe that the wave of interest will not decline, as it happened in the 1950s because the shooting and projection equipment is now much better. Movie studios instantly responded to a positive reaction from the public - and dozens of stereo films are currently under development. To achieve the goal, all the tools are worthy, so some of the paintings are not removed, but programmatically converted to $3 \mathrm{D}$, which is fierce criticism. If you watch the movie titled "The Battle of the Titans" (2010), you can see the case of the justified critique.

Recent films have eloquently testified that with the help of modern digital technologies, artists can bring everything on screen to power. The restriction is only the production budget, terms, and imagination of the people. But it should be remembered that the success of the viewers is due not so much to the visual effects as to the story itself. Computer graphics and special effects, combined with the stuntman's work, only complement, serve as a tool in the hands of a talented director for storytelling, script rendering. When trick effects are created for their own sake, then cinema ceases to be art and turns into an attraction, as it is now. 
These kinds of films can be earned through marketing, but they are sure to be quickly forgotten. In the years to come, "Avatar" is awaiting us with many 3D movies packed with visual gimmicks. The pleasure for the eyes is ensured. Still, without the exciting content part, the shelf life of such projects is not great because technologies are continually evolving, and many CG achievements in 5-7 years become anachronistic, although they were once considered advanced. It's hard to imagine that in 7-10 years, people want to watch "The Battle of the Titans," unlike "Terminator 2: Judgment Day", which loses as a show but wins as a movie ${ }^{6}[2]$.

Computer graphics studios will continue to emerge around the world, as demand for visual effects and graphics will only increase every year. Software prices are plummeting; computer power is growing, so even low-cost producers can afford the graphics. As for the CG companies of the lead group, they will mostly have to work with 3D material, as the main blockbusters will not avoid the fate of gaining additional volume. In addition, much of the fantasy films that require the creation of a whole new world will be filmed using virtual production technology. However, the dominance of CG technology does not mean that cinematographers will no longer build scenery, layouts, and apply physical trick effects. All this will be due to the reason that not every creative task is cost-effective to solve on a computer ${ }^{7}$ [2].

To summarize, let us highlight the stage films of the last period.

"Final Fantasy" (2000). The first full-length 3D film by director Hironobu Sakaguchi, whose characters were created on scans of real actors and animated using motion capture techniques. Despite the visible technological innovations, the picture experienced a complete failure in the rental. In addition to high-quality CGI, the tape can add to the asset the fact that a virtual heroine named Aki Ross developed so spectacular that she was on the list of 100 sexiest women by Maxim magazine.

"The Lord of the Rings" (film series) (2001, 2002, 2003). The legendary trilogy made by Peter Jackson, which put the Weta Digital studio on par with the leader of the visual effects industry - Industrial Light \& magic. First of all, the project is notable for the realistic character Gallum. In the field of the technique of capture and transfer of an actor game, the tape became the real breakthrough. In addition, a Massive software tool was developed under the battle scenes of the film to allow digital models of characters driven by artificial intelligence to be created. All three films received an Academy Award for

6 Мееров К (2012) Исторический экскурс во вселенную спецэффектов III. Профессиональный журнал о спецэффектах в кино CINEFEX. URL: http://www.broadcast. telekritika.ua/show/TSifrovoij_kinematograf/2028-istoricheskiij_jekskurs_vo_vselennuju_ specjeffektov_chast_2_18.05.2012.

${ }^{7}$ At the same place.URL: http://cinefex.ru/articles/detail.php?ID $=442$. 
visual effects. Previously, only the first three films of the Star Wars movie franchise were awarded such an honor.

"King Kong" (2005). This project, directed by Peter Jackson, brought to the Weta Digital studio another Academy Award-winning visual. The picture stuns CGI characters, especially King Kong, who was animated again with the use of an actress capture technique, refined compared to The Lord of the Rings. In addition to the animals, the tape strikes the scenes in New York of the 1930s that were recreated from photographs of those years.

"The Pirates of the Caribbean trilogy" (2003, 2006, 2007). Each part of the Gore Verbinski director trilogy was able to make a significant contribution to the development of CG technologies. The second film was awarded the Academy Award for visual effects. A new Imocap motion capture system was proposed, which made it possible to read the movements of the actors directly on the set without having to hold a separate session in the pavilion within a specific work area called Volume. The third film made a breakthrough in the field of continuous media simulation. Water and swirl in the finale of the trilogy marked a significant step forward with The Maelstrom software tool.

"The Mysterious History of Benjamin Button" (2008). Director David Fincher's breakthrough movie. For the first time in history, computer graphic artists have been able to create a photorealistic human character, or rather a head that has been cast into the body of a real actor. In order to achieve stunning reliability, professionals needed to improve several aspects of the work at once: texturing, shading, and animation. The effort was crowned with an Academy Award for visual effects.

"Avatar" (2009). Director James Cameron's highest-grossing movie in movie history is $60 \%$ computer-generated. All in all, in the picture, lasting over 2.5 hours, only 15 plans did not touch the hand of computer graphics specialists. Avatar's release marked the beginning of a new phase in the production of stereo films. In addition, the makers of the film have proposed a technique of the virtual output, which is sure to change the process of creating films with many graphics, where many scenes are generated in 3D. The project was projected to be awarded the Academy Award for Best Visual Effects ${ }^{8}$ [2].

"Mad Max: Fury Road" (2015). The director of the film is George Miller (budget - from \$ 150 million). "Mad Max: Fury Road" was heavily color-coded and complemented by seamlessly mixed CGI landscapes, dust storms, and flames - all of which are extremely impressive. But what sets Fury Road the absolute pinnacle of modern special effects is its creative, death-defying, practical trick work, which, according to Miller, accounts for 90 percent of the

${ }^{8}$ Meerov K (2012) Historical excursion into the universe of special effects III. Professional'nyy zhurnal o spetseffektakh v kino CINEFEX. RL: http://cinefex.ru/articles/detail. php?ID =442. 
effects used in the film. The raw production footage shows crazy accidents, explosions, and flips made on custom-made post-apocalyptic moving vehicles. This is a real stuntman tied to the front of a wall of speakers, playing the guitar equipped with a real flamethrower, and real people dangerously running back and forth on flexible poles when tons of raw metal cast their eyes on the ruthless desert beneath them. Witness! (Katie Rife) ${ }^{9}$.

"The Walk" (2015). With his usual mastery of cutting-edge technology, Robert Zemeckis dramatizes the famous high-wire artist Philip Petit, made between the two towers of the World Trade Center. Using 3D technology most impressively, Zemeckis takes his cameras and lifts the viewer high above the ground, placing them on a wire and creating a stunning view of walking height. Petit looks visually real. It transforms a sight we cannot forget into an experience we do not want to experience. (Alex McLevey) ${ }^{10}$ [4].

Doctor Strange (2016). An American superhero movie made by Scott Derrickson. This movie was nominated for an Oscar for the most contemporary special effects in cinema history, as well as for costumes. For the beautiful picture in response, the legendary company Industrial Light \& Magic, famous for working on all parts of Star Wars. Following the line of comic book creator, artist Steven Ditko, who found inspiration in the works of Salvador Dali and Dutch artist Maurice Escher, the company has created a universe of intricate three-dimensional objects with remarkable plasticity. Forty-nine painters worked on the film, whose efforts created about 4000 drawings and sketches and more than 40 tiny layouts of locations. Costume designers have made incredible efforts. The Doctor's only one levitation cloak was made in 18 variants with unique modification for each scene ${ }^{11}$ [4].

Jurassic World 2 (2018). American fantasy film directed by Juan Antonio Bayon, the fifth film in the Jurassic Park series. Created by Colin Trevorrow and Juan Antonio Bayon ${ }^{12}$ [5]. According to Bayon, the scenario of the movie involves a considerable ethical dilemma. Against the backdrop of a glowing volcano ready to melt everything viable within sight, the protagonists have to choose: will they save the lives of such a cozy neighbor of all living things, or will they relinquish empathy and allow a revived wonder of nature to grow into a roaring fire? The team responsible for the special effects in the picture is led by artist Neil Scanlan, who won the Academy Award for Big

${ }^{9}$ The 50 greatest special effects movies of all time. URL: https://film.avclub.com/the-50greatest-special-effects-movies-of-all-time-1827830379.

${ }^{10}$ At the same place. URL: https://film.avclub.com/the-50-greatest-special-effects-moviesof-all-time-1827830379.

11 The main contender for the Oscars: how the Doctor Strand was filmed. URL: http://www.wday.ru/stil-zhizny/novosty/doktor-strendj-kak-sozdavalsya-film-i-stoit-li-na-nego-poyti.

${ }^{12}$ Star Wars 9 Cast Table Read Is Happening Soon. URL: https://movieweb.com/star-wars9-script-cast-table-read/. 
Animal Anti-Epic Survival "Babe" and (even more revealingly) supervising visual digital operations in all recent episodes of "Star Wars" (for which he received the 2016 BAFTA Award for Best Visual Effects Achievement). The task was simple, but at the same time, difficult in technical terms - the masters need to make the monsters look as realistic as possible. Therefore, to create the effect of presence was used animatronics (a masterful technique for creating electronic dolls, robots, etc.), which sometimes allowed to do without computer graphics. The work was done so professionally that one of the dinosaurs, Blue, was perceived as alive by some of the crew. Neil Scanlan said that he and his team were very interested in working on Indoraptor as a representative of a failed experiment - and in conveying it in the frame, the authors represent a scent while bits of skin are dropping out ${ }^{13}$ [7].

\section{CONCLUSIONS}

The emergence of computer technology in cinema by value can be compared to the invention of audio. Today it is certainly possible to shoot following the old times. But in doing so, one must be aware of the deep abyss where such cinema will be located.

With the development of digital technologies, artistic and entertainment forms (stage and screen) have expanded the range of their expressive means, including trick special effects. Such elements of the new artistic reality exert a significant influence on the psychology of aesthetic perception. In theatrical activities, computer graphics, laser installations, and other advanced inventions that create virtual and interactive tricks on stage are actively used. The advent of digital cinema has emerged in a large number of computer-generated special effects, whose genesis has been traced. Demand for visual effects and graphics is projected to grow, 3D technology will be used, and trick movies will continue to evolve.

The computer helped to complete the entire stage of filmmaking - the materialization of miracles from the handymen in front of the camera (to perpetuate them on film and immediately throw ones into a landfill). Nowadays, any of the most incredible designs can be born directly on the screen. Cinema has finally ceased to be the only screen art, becoming a television and a computer. The fantastic image ceased to be only a reflection of the fake reality and became itself - a fiction utterly independent of the cinematic life temporality ${ }^{14}$ [3]. With the advent of computer technology, there are unlimited opportunities for the production of trick movies.

${ }^{13}$ Video: how dinosaurs were created in Jurassic World 2. Kinokratiya. URL: https://rg.ru/2018/05/21/video-kak-sozdavali-dinozavrov-v-mire-iurskogo-perioda-2.html.

14 The history of cinema. Kratkiy ekskurs $\mathrm{v}$ istoriyu spetseffektov. URL: http://www.mirf.ru/Articles/print137.html. 
We see the prospects for further scientific research in an in-depth study of the trick component of modern art and entertainment forms to develop a new scientific direction - special effects (trick) science.

\section{SUMMARY}

The article analyzes the evolution of computer cinema from the creation of simple graphic images on a computer to the rendering of the most fantastic ideas. It gives examples of films that have made a breakthrough in filmmaking through the combination of physical and visual effects.

\section{REFERENCES}

1. Terakopyan M. L. (2007) Back to the Future: Computer Technologies in Cinema. Iskusstvo kino, 9, pp. 65-71.

2. Meerov K (2012) Historical excursion into the universe of special effects III. Professional'nyy zhurnal o spetseffektakh v kino CINEFEX. URL: http://cinefex.ru/articles/detail.php?ID $=442$.

3. The history of cinema. Kratkiy ekskurs $\mathrm{v}$ istoriyu spetseffektov. URL: http://www.mirf.ru/Articles/print137.html.

4. The 50 greatest special effects movies of all time. URL: https://film.avclub.com/the-50-greatest-special-effects-movies-of-all-time1827830379 (дата відвідування 03.10.2018).

5. The main contender for the Oscars: how the Doctor Strand was filmed. URL: http://www.wday.ru/stil-zhizny/novosty/doktor-strendj-kaksozdavalsya-film-i-stoit-li-na-nego-poyti/.

6. Star Wars 9 Cast Table Read Is Happening Soon. URL: https://movieweb.com/star-wars-9-script-cast-table-read/ (дата відвідування 16.09.2019).

7. Video: how dinosaurs were created in Jurassic World 2. Kinokratiya. URL: $\quad$ https://rg.ru/2018/05/21/video-kak-sozdavali-dinozavrov-v-mireiurskogo-perioda-2.html.

\section{Information about the author: Zhukovin O. V., orcid.org/0000-0003-1499-9380 \\ Candidate of Art Science,} Associate Professor of the Directing and Acting Department National Academy of Culture and Arts Management 9, Lavrska str., Bldg. 15, 01015, Kyiv, Ukraine 